\title{
The Impact of Internal Control Quality on Accounting Conservatism
}

\author{
Shan-shan Yang, Yun-li Qiao \\ Department of Management, Wuhan University of Technology, Hubei Province, China
}

\begin{abstract}
This paper establishes the evaluation index system of the quality of internal control of commercial banks. Then the paper combined with the improved adding calculated by entropy method within the accrual cash flow model of quality control index, the presence of internal control and the level of accounting conservatism were considered. This paper aims at figuring the relationship between the ability to internal control and accounting conservatism of listed commercial banks through the study, the representative of the financial field of the enterprises to strengthen internal control system to establish and improve the theoretical basis of information disclosure quality.

Index Terms - The quality of internal control; Accounting
\end{abstract} Conservatism; Listed commercial banks.

\section{Introduction}

Internal control is a key of corporate governance. Internal control and risk management in the modern meaning of our country has experienced three stages: Before 1980s, the enterprise risk management mainly includes the insurable risk management and financial risk control and mainly reduce the loss by the purchased insurance; in 1980s, Reform and Opening-up was implemented, promoting the rapid development of enterprises and a lot changes in the overall economic environment in our country. How to set up a management system according to one's own risk has become a problem to be solved; since the beginning of twenty-first century, enterprise risk management has been paid more and more attention. In 2014 September, the CBRC announced a revised edition of the "commercial bank's internal control guidelines", to the sound operation of commercial banks to consolidate the idea, improve the ability of the sustainable development of enterprises, maintain the stability of the domestic financial market. This shows that the commercial banks as the domestic financial industry benchmark, the level of risk management and internal control quality is more and more enthusiastic attention of the state and society. Besides, accounting conservatism is one of the eight standards of accounting information. Its basic meaning is included in the realization of the principle of income and all possible loss calculation based on enterprise income. The better the accounting conservatism is, the stronger the risk control ability will be.

About the quality of information disclosure of internal control to quantify, Ref. [1] was proposed by JinFei, Zhu Yonghua. They thought visual information disclosure of information disclosure and the number of pages could be considered as the evaluation standard of internal control. Ref. [2] was proposed by Zhang Guoqing. In his research on internal control quality, the assessment concluded the company self-assessment report, external auditors, sponsors and the board of directors or the supervisory board of the internal control evaluation could reflected the quality of internal control. Ref. [3] was proposed by Kong Fanfeng. He collected several listed Corporations' evaluation report of their internal control, and provide the audit report opinion type, in which the firm of listing Corporation in the stock exchange to be punished as a judgment of whether the company has major defects based on the internal control. Ref. [4] was proposed by Zhang Xiaolan, Shen Haojie, Yang mo. They] chose13 index form the self-evaluation and audit reports of the internal control in the listed Corporation based on COSO internal control framework concept. By using means of entropy model, he established the calculation method of internal control quality named ICDQ from two aspects of relevance and reliability. Not only does the internal control information index constructed by this method involves many aspects of the information objectively, but also can it reflect the quality differences between enterprises effectively.

Overall, the research on quality of information disclosure of the internal control of the company went through three stages. First, the level of detail by enterprise internal control disclosure of information, this method was lack of objectivity, and using the amount of information as the criterion of effective information was not accurate. Second, utilize dummy variables like 0 or 1 to quantify the quality of internal control. If large amount of data processing, the tedious work of the case, this approach can reflect the advantage, but for some data internal audit report, this method would neglect the accuracy of information. Third, compared to the previous methods, the use of entropy model has two advantages, one is the internal control information can cover many enterprises finally, as a comprehensive index to reflect the results. Another is that when the information to consider become variable, model can also hold them. Therefore, this paper uses the entropy model to calculate the data quality of internal control of listed commercial banks

About the study on measurement method of accounting conservatism, Ref. [5] was proposed by Basu. He proposed surplus stock returns the inverse regression measurement method (AT), using the timeliness of accounting conservatism and the properties of inverse coefficient in the regression model to reflect the economic losses in earnings. In order to figure the enterprise's accounting conservatism, Ball and Shivakumar thought AT method was born in the condition that America securities market so the effectiveness of the market 
should be higher. On the stability considerations, they proposed cash flow measurement method (ACF)applied to no market data accrual. Having compared and selected for a variety of measurement methods of accounting conservatism, Zhang Zhaoguo, Liu Yongli, Ref. [5] was proposed by Li Gengqin who obtained the two measurement methods of AT and ACF from different aspects of firm robustness. They thought the two methods can be used in conjunction with the conclusion. In fact, each method has certain application conditions as long as the background has been fully considered.

In order to study the relationship between the internal control quality and accounting conservatism, Qi Baolei used significant accounting errors as a proxy for defect of internal control, as a measure of internal control quality on the influence of conservatism. Fang Hongxing, Zhang Zhiping proved by the accrual and cash flow model that when the company's disclosure of internal control information is of high level, the information of economic losses will be figured fast. Xiao Hua, Zhang Guoqing (2013) proposed a method similar to Sloan to measure the earnings persistence. Tobin Q said the value of the company and empirical data said the quality of internal control and earnings persistence, positive correlation between accounting conservatism. Guo Yue, Pei Wenjun (2014) put forward the quality of internal control and accounting conservatism is positively related by using the theory and method of measurement - surplus stock returns model. All the detailed explanation of the quality of accounting conservatism and corporate internal control has been made. But for commercial banks which represent special financial industries, there still exists some unfold places. Therefore, this paper makes more detailed analysis of historical data of listed commercial banks.

\section{Valuation Indicator System of Internal Control}

According to Zhang Xiaolan (2012)'s part of [5] research as the basis, the paper selected the possible quality of internal control factors as the internal control quality indicators for the evaluation of internal control. The entropy model could calculate the internal quality control index of listed commercial banks. As the following shows:

TABLE I Valuation indicator system of internal control

\begin{tabular}{|c|c|c|c|}
\hline \multicolumn{2}{|c|}{ Primary Indicators } & Secondary indicators & Explanation \\
\hline \multirow{5}{*}{ Relevance } & \multirow{3}{*}{ The contents of disclosure } & The internal control deficiencies has been published F1 & $\begin{array}{l}\text { No disclosure }=1 \\
\text { General weakness=3 } \\
\text { Material weakness=5 }\end{array}$ \\
\hline & & The internal control reports conclusions has been issueF2 & $\begin{array}{l}\text { It has the conclusion=1 } \\
\text { It hasn't the } \text { conclusion=5 }\end{array}$ \\
\hline & & Internal control self-assessment report F3 & $\begin{array}{l}\text { It has the report }=1 \\
\text { It hasn't the report=5 }\end{array}$ \\
\hline & \multirow{2}{*}{ The form of disclosure } & The audit report of internal control F4 & $\begin{array}{l}\text { It has the report=1 } \\
\text { It hasn't the report=5 }\end{array}$ \\
\hline & & The effectiveness of internal control evaluation F5 & $\begin{array}{l}\text { Effective=1 } \\
\text { Invalid=5 }\end{array}$ \\
\hline \multirow{3}{*}{ Reliability } & External supervision & Audit firm F6 & $\begin{array}{l}\text { The big four }=1 \\
\text { Others }=5\end{array}$ \\
\hline & \multirow[t]{2}{*}{ Internal supervision } & The proportion of independent directors F7 & $\begin{array}{l}{[0.4, \infty]=1} \\
{[0.3,0.4]=3} \\
{[\infty, 0.3]=5}\end{array}$ \\
\hline & & Chairman and general manager is the same personF8 & $\begin{array}{l}\text { No concurrent post }=1 \\
\text { Concurrent post }=5\end{array}$ \\
\hline
\end{tabular}

The table is the meaning of quality evaluation of internal control according to table 2 the statistics from 2010 to 2013, scoring in each section of the bank accounts for the total number of proportion. The internal control deficiencies disclosure situation, the listed commercial banks maintain no internal control deficiencies in 3 years, a few banks in 2011 and 2013 general defects and major defects, including general defects were appeared 10 times, accounting for the proportion of the overall $15.63 \%$ major defects, only once; in the self evaluation report, the report is issued conclusion the effectiveness of internal control evaluation report and internal control, the overall level of $93.75 \%$ from 2010 to 2011 to $100 \%$ issued a report, and until 2013 , during this period, only one bank in 2010 did not issue a report and conclusion; similarly, whether the audit report issued by the internal control, because there are two banks not issued the annual audit reports from 2010 to 2012 could not determine whether the audit activities and audit firms are the four major accounting firms, the removal of these, 16 listed commercial banks overall level of the audit report issued on the rise, to 2013, all banks will audit by the big four accounting firms and management, all the audit report issued by the internal control in the enterprise internal governance; all enterprises in the proportion of independent directors, the overall performance is increasing, can represent the shareholders and managers, can enhance and make independent judgments on the enterprise decision-making forces independent enterprises from a certain extent, "and the chairman and general manager of the two level one" phenomenon did not occur, reflecting the 16 listed 
commercial banks internal control quality continuous improvement.

\section{Entropy Model of Internal Control Quality Index}

A. Establish the Evaluation Item Set

$$
A=\left(\begin{array}{cccc}
a_{11} & a_{12} & \cdots & a_{1 j} \\
a_{21} & a_{22} & \cdots & a_{2 j} \\
\cdots & \cdots & \cdots & \cdots \\
a_{i 1} & a_{i 2} & \cdots & a_{i j}
\end{array}\right)
$$

The item $a_{i j}$ represents the sore that the commercial bank i get in the aspect $j$.

B. Unifying the Index

$b_{i j}= \begin{cases}\min a_{i j} / a_{i j} & a_{i j} \in I_{1} \\ a_{i j} / \min a_{i j} & a_{i j} \in I_{2}\end{cases}$

$I_{1}$ represents the index which is positive, the bigger the better, while $I_{2}$ is exactly the opposite.

\section{Determine the Weight Matrix}

$p_{i j}=b_{i j} / \sum_{i=1}^{m} b_{i j}$

To be noted that $p_{i j}$ represents the company $j$ 's score of the index $i$.

\section{Make Detailed Calculation}

First, the paper calculate the $\mathrm{j}$ index's entropy $H_{j}$ and the weight entropy $w_{j}$.

$$
\begin{aligned}
& H_{j}=-k \sum_{i=1}^{m} p_{i j} \ln p_{i j}(j=1 ? n) \\
& w_{j}=\left(1-H_{j}\right) /\left(n-\sum_{i=1}^{m} H_{j}\right) \\
& k=1 / \ln m
\end{aligned}
$$

To make it clear, the bigger the $H_{j}$ is, thegreater the amount of information is in the $\mathrm{j}$ index in the bigger, the better the results.

Then the paper calculate the index of internal control quality $I C Q$.

$$
I C Q=\sum_{j=1}^{8} w_{j} a_{i j}
$$

\section{The Improved Accrual Cash Flow Model}

A. Symbols and Explanation

TABLEII The Symbol and Explanation

\begin{tabular}{|c|c|}
\hline ACCRUAL & (Net Profit-Business Cash Flow) / Total Assets \\
\hline CFO & Business Cash Flow/ Total Assets \\
\hline DCFO & $\left\{\begin{array}{l}0, C F O \geq 0 \\
1_{2} \text { CFO }<0\end{array}\right.$ \\
\hline ICQ & Internal Control Quality Inde \\
\hline STR & Power of Control - Ownership \\
\hline LEV & The Asset - Liability Ratio \\
\hline SIZE & In(Total Assests) \\
\hline
\end{tabular}

\section{B. The establishment of improved accrual cash flow model}

Based on the cash flow measurement model, the paper add ICQ and STR to the model, the improved one is as follows:

$$
\begin{aligned}
A C C R U A L= & \gamma_{0}+\gamma_{1} D C F O+\gamma_{2} C F O \\
+ & \gamma_{3} D C F O \times C F O+\gamma_{4} I C Q \\
+ & \gamma_{5} I C Q \times D C F O+\gamma_{6} I C Q \times C F O \\
& \quad+\gamma_{7} I C Q \times D C F O \times C F O \\
& +\gamma_{8} S T R+\gamma_{9} L E V+\gamma_{10} S I Z E+\varepsilon
\end{aligned}
$$

According to this model, this paper has the following inference:

(1) In accrual - cash flow model, the operating cash flow as a representative $\mathrm{CFO}$ reflect the amount of economic benefits or economic losses. Positive and negative and value of coefficient ACCRUAL and 10 months after the project can reflect the relationship between ACCRUAL and the corresponding project from a certain extent. The calculation method of accruals ACCRUAL point of view, it is the operating cash flow minus the revised net profit as the denominator. Therefore, the direction of change in ACCRUAL and operating cash flow CFO should instead, which is negative;

(2) The basic requirement of accounting conservatism is the recognition of income should be based on the implementation of the principle, the possible economic losses should be fully considered, or that the sensitivity of economic loss information should be higher than the income information. Therefore, if there exists the accounting conservatism, the negative correlation between ACCRUAL and CFO should be stronger.

(3) Meaning is the quality control factors including internal negative cash flows of the project, including the index of the quality of internal control ICQ is a negative index (smaller values, on behalf of the enterprise information disclosure of internal control quality more reliable) 
If weak internal control would have negative effect on accounting conservatism, the negative correlation among ICQ and CFO and DCFO will be weakened.

(4) The choice of a commercial bank, taking into account the financial data, the internal control of the listed commercial banks have been more complete, this paper includes 5 stateowned banks and 11 joint-stock commercial banks, 16 listed commercial banks as the object of statistics. Among them, 14 commercial banks listed before 2010, only the Agricultural Bank and China Everbright Bank listed China late, missing data. This paper in 2010 as the research starting point, on the 16 listed commercial banks from 2010 to 2013 a total of 4 years of data analysis. On the data, this paper find commercial bank in Tai'an and CSMAR Chinese listing Corporation financial statements database, China listing Corporation internal control research database to obtain the annual report data of 16 commercial banks and internal control selfassessment report data as sample data.

\section{Conclusion and Discussion}

The paper conclude that accounting conservatism is an important part of enterprise risk management activitiesas it is an effective way to control the financial risks of enterprise. The internal control of enterprise information quality is a standard to measure the effect of enterprise risk management. On top of that, the enterprise accounting conservatism has a promoting effect on the improvement of the internal control system. This paper aims at an empirical study of relationship between internal control quality and enterprise accounting conservatism, hoping to lay a theoretical foundation of strengthening the internal control system and improving the of information disclosure quality.

Commercial banks as an important hub to promote the flow of money in the financial market, the company's stable development is closely related to the economic environment. To improve the enterprise internal control effect and information disclosure quality, can guarantee the enterprise financial accounting system and robust sustainable, and can maintain the stability of the whole financial market. This paper aims at an empirical study of internal control quality and enterprise accounting conservatism and the relationship between the listed commercial banks in the industry analysis, to strengthen the internal control system to establish and improve the theoretical basis of information disclosure quality.

\section{References}

[1] Jin Fei, and Zhu Yonghua, Listed Company Internal Control Information Disclosure Quality. Journal of Wuhan Institute of Technology. 2009(8), 121-124.

[2] Zhang Guoqing. Internal Control and The Quality of Surplus: Based on the Empirical Data of A Shares of the Company. Management of Economy. 2008(12), 27-29.

[3] Kong Fanfeng. The Defects of Internal Control and The Cost of Debt. Journal of Guangdong University of Business. 2012(3), 51-55.

[4] Zhang Xiaolan and Shen Haojie and Yang Mo. Study on the quality of internal control information disclosure index model based on Entropy Measurement. Journal of Xi'an Jiao Tong University.( Social Science Edition) 2012(1), 49-52.

[5] Basu S, The Conservatism Principle and the Asymmetric Timeliness of Earnings . Journal of Accounting and Economics, 1997,183-185.

[6] Givoly,D.C.Hayn,andA.Natarajan. Measuring Reporting Conservatism, Accounting Review, 2006,110-121.

[7] Ball,R., L.Shivakumar. Earnings Quality in UK Private Firms: Comparative Loss Recognition Timeliness. Journal of Accounting and Economics,2005,83-85. 